\title{
Hematemesis in a Newborn: A Case Report
}

\author{
Jasmeet Kataria-Hale $^{1}$, Liz Febo-Rodriguez ${ }^{1}$, Shweta Parmekar ${ }^{2}$ \\ 1. Pediatrics, Texas Children's Hospital, Houston, USA 2. Pediatrics, Baylor College of Medicine, Houston, USA
}

Corresponding author: Jasmeet Kataria-Hale, kataria@bcm.edu

\section{Abstract}

We present the case of a term-healthy neonate who developed hematemesis while being admitted at the newborn nursery. The infant was found to have gastric ulcers with duodenal eosinophils. The condition was conservatively managed and the symptoms, including ulcers, resolved with time; however, the etiology of the ulcers is still unknown.

Categories: Pediatrics, Gastroenterology, Other

Keywords: hematemesis, melena, newborn, eosinophils, ulcer

\section{Introduction}

Peptic ulcers and upper gastrointestinal (GI) bleeding mostly occur in critically ill patients secondary to physiologic stress [1]. The differential for GI bleeding includes medication side-effects, infection, coagulopathy, milk protein allergy, and vascular or anatomic anomalies [2]. Although primary duodenal ulcers are rare in neonates, gastric ulcers usually occur in the setting of serious underlying illness [3]. In addition to physiological stress, perinatal events that disturb GI tract circulation have been suspected in cases of gastric ulcers. We describe a case of a term-healthy neonate who developed hematemesis and melena due to primary gastric ulcers without a known inciting perinatal event.

\section{Case Presentation}

A one-day-old, East Asian, 3,890-gram term male baby, born to a 31-year-old G3P1021 mother via spontaneous vaginal delivery, developed blood-tinged emesis in the newborn nursery. The mother reported good prenatal care, negative screening labs, prenatal vitamin intake, and no tobacco, alcohol, or illicit drug use. The pregnancy had been uncomplicated. There had been no concern for or symptoms of maternal Helicobacter pylori (H. pylori) infection. She had presented in active labor with clear amniotic fluid and had had an uncomplicated delivery. APGAR scores had been 8 and 9 at one and five minutes, respectively. Vitamin $\mathrm{K}$ had been given at birth.

Received 10/07/2019 Review began 10/11/2019 Review ended 01/22/2020 Published 01/27/2020

\section{(c) Copyright 2020}

Kataria-Hale et al. This is an open access article distributed under the terms of the Creative Commons Attribution License CC-BY 3.0., which permits unrestricted use, distribution, and reproduction in any medium, provided the original author and source are credited.
The infant had initially breastfed, though one feed of term formula had been given due to inadequate breastmilk, followed by the occurrence of blood-tinged emesis. No maternal nipple bleeding had been reported. Vital signs were within normal limits and physical exam was reassuring. On day of life (DOL) two, the infant developed melena.

A complete blood cell count showed a white blood cell count of $28 \mathrm{~K} / \mathrm{uL}$ with $58 \%$ neutrophils, hemoglobin of $15 \mathrm{~g} / \mathrm{dL}$, hematocrit of $43 \%$, and platelet count of $255 \mathrm{~K} / \mathrm{uL}$. Within 24 hours, the subsequent hematocrit was found to be $27 \%$ and packed red blood cells were transfused. Chemistries, liver panel, and coagulation studies were unremarkable. An abdominal radiograph revealed nonspecific, mildly dilated, and featureless right lower quadrant bowel loops. Blood culture showed no growth. Apt-Downey test and serum viral studies were negative. A stool panel was negative for bacteria and parasites. The gastrin level was normal.

Initially, feeds were withheld; intravenous fluids, empiric antibiotics, and acyclovir were administered, and a nasogastric Replogle tube was placed. The gastroenterology team was consulted and an esophagogastroduodenoscopy (EGD) was performed on the fourth DOL. The EGD showed normal esophageal mucosa, extremely friable and erythematous gastric folds, multiple superficial small ulcers without active bleeding within the antral mucosa, two stellate ulcers in the gastric body, and friable and erythematous duodenal folds without ulceration (Figures 1,2). 


\section{Cureus}

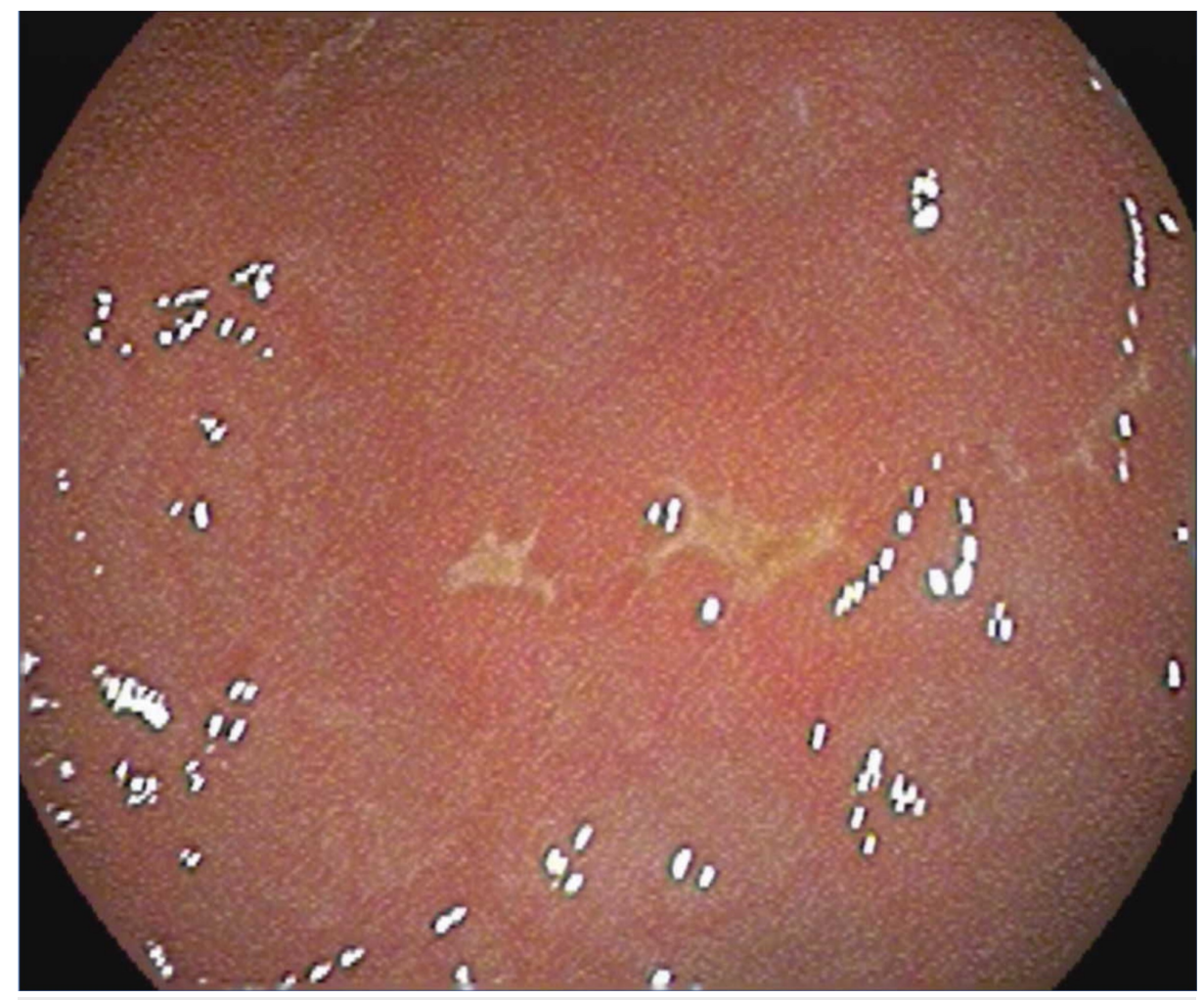

FIGURE 1: EGD showing multiple stellate gastric ulcers

EGD: esophagogastroduodenoscopy

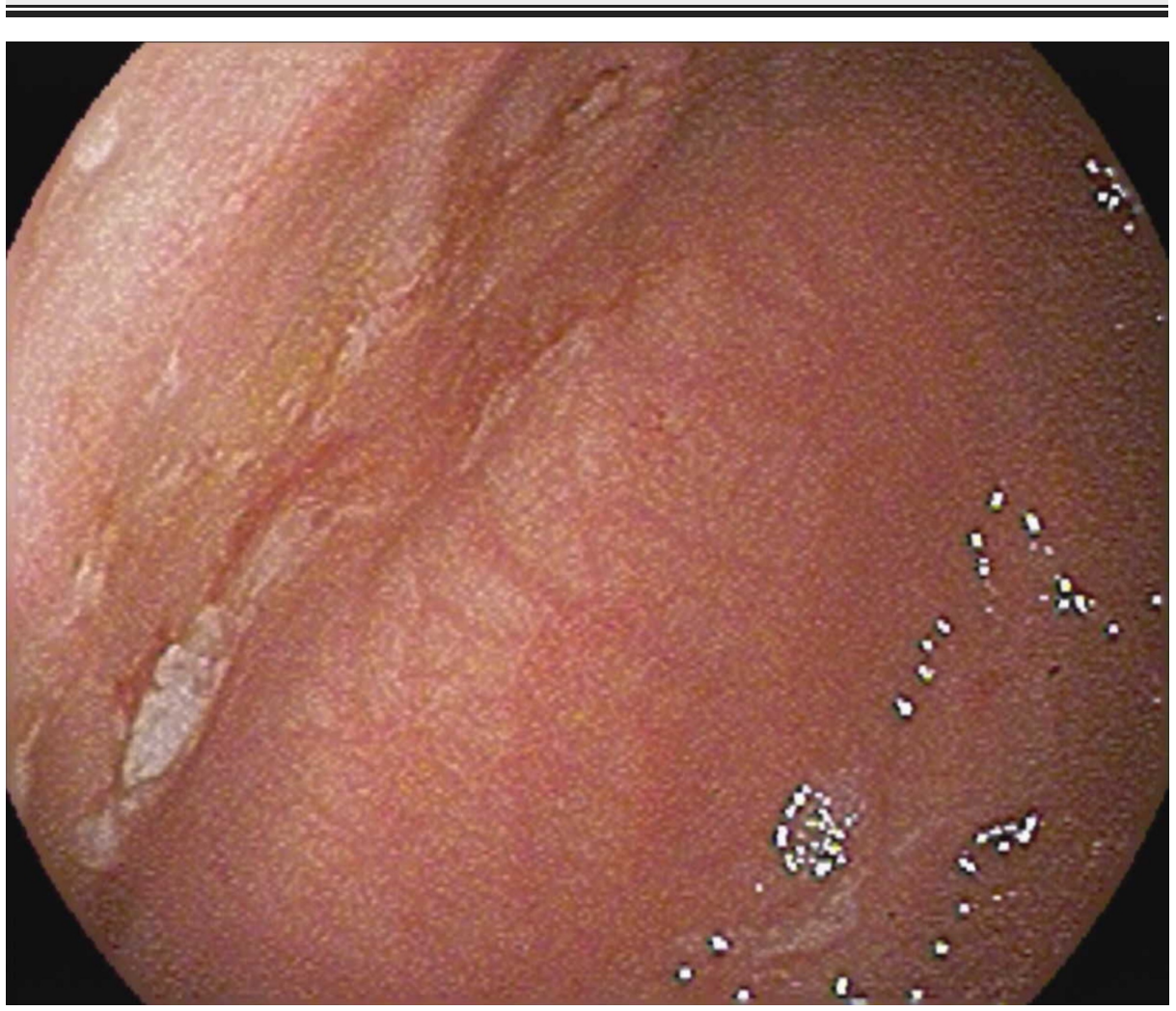

FIGURE 2: EGD showing large healing gastric ulcer that demonstrates stigmata of previous bleeding

EGD: esophagogastroduodenoscopy 
The duodenal biopsy was negative for H. pylori; however, it showed a focal superficial aggregation of eosinophils. Pantoprazole was empirically started. The hematemesis and melena self-resolved on the fourth DOL. The infant was discharged on the eighth DOL on full feeds and lansoprazole without recurrence of symptoms.

\section{Discussion}

The majority of peptic ulcers in critically ill neonates are secondary to physiologic stress, such as shock, respiratory failure, sepsis, hypoglycemia, severe burns, and intracranial lesions. In addition to postnatal events, perinatal ones may contribute to peptic ulcer development in neonates. These include asphyxia, prolonged labor, instrumentation, Caesarean section, and even social stress [1,3-7]. Asphyxia as a result of circulatory disturbances of the GI tract can cause mucosal ischemia and resultant peptic ulcers.

Physiological stress can impair the normal homeostasis that is maintained in the gastric mucosa, causing the formation of both superficial and deep erosions. These erosions can spread and deepen, eventually causing perforation [1]. This case is unique in that, despite a thorough work-up, a definitive etiology was unidentified; hence it indicates the need for considering the role of perinatal stress in neonatal ulcer development.

After an uncomplicated delivery, the infant was admitted to the nursery, thereby decreasing the likelihood of postnatal physiologic stress as the cause of ulcers. Zollinger-Ellison syndrome was considered, but the gastrin level was normal. Given that melena occurred following formula intake, an immunoglobulin Emediated cow's milk protein allergy was considered, but the temporal relationship of symptoms after one feed and lack of hematochezia made this less likely [8]. The focal superficial aggregation of eosinophils in the duodenum on EGD is unique. In adults, eosinophils in the stomach and duodenum are thought to be a secondary response to chronic inflammation due to $\mathrm{H}$. pylori infection, which was negative in this case. Another consideration was that eosinophils can accumulate in the GI tract due to food allergies, but is highly unusual in the newborn period. Despite the duodenal eosinophils, the patient did not meet diagnostic criteria for eosinophilic duodenitis and thus is an unlikely explanation for the ulcers $[9,10]$.

Following discharge, during a retrospective inquiry, the mother revealed that she had experienced significant psychosocial stress throughout her second trimester of pregnancy. A natural disaster had caused substantial upheaval in her life, including evacuation from her home while preparing for childbirth. Moreover, she had been working two jobs with very little family support. To the best of our knowledge, there are few reports that associate gastric ulcers with psychosocial factors. However, the literature supports the concept that exposure to prenatal stress can disrupt the health and development of the fetus [11]. In this case, the psychosocial stress that the mother faced during the pregnancy may be associated with the development of ulcers. A case by Pugh et al. have described the case of an infant with fatal bleeding during the first DOL due to gastric ulceration. It was suspected to be associated with significant maternal social stress during the third trimester of pregnancy caused by maternal hormone transplacental transfer [7]. Gastrin has been previously implicated in such cases, but recent reports question the transplacental passage of this hormone to the human fetus and the role it plays in isolated ulcer development [12]. Matsueda et al. have presented a case of a stress-induced gastric ulcer in a previously healthy toddler possibly due to psychological stress [13]. The effect of perinatal stress during pregnancy on gut development in neonates has been rarely reported and further work in this area is required. At the time of this report, the infant is 19 months old with no reported GI bleeding or food allergies.

\section{Conclusions}

This case demonstrates the potential for a healthy term infant with no known inciting factors to develop gastric ulcers. In severe or difficult cases, such as in this patient, an endoscopy may be helpful for diagnosis and potential therapeutic management. The case highlights the importance of conducting a thorough history, including prenatal maternal stressors and events, to assess possible causes for neonatal ulcers. Given the eosinophils in the duodenum, this case could represent the early findings of a food allergy; but due to the difficulties to diagnose in the newborn period, the infant would require further evaluation in childhood. This early knowledge could be predictive of future diagnoses. The etiology of the bleeding continues to be elusive and further exploration is needed, especially on the neurobiology of perinatal stress and its role in intestinal development, to help in the early identification and diagnosis of the condition.

\section{Additional Information \\ Disclosures}

Human subjects: Consent was obtained by all participants in this study. Conflicts of interest: In compliance with the ICMJE uniform disclosure form, all authors declare the following: Payment/services info: All authors have declared that no financial support was received from any organization for the submitted work. Financial relationships: All authors have declared that they have no financial relationships at present or within the previous three years with any organizations that might have an interest in the submitted work. Other relationships: All authors have declared that there are no other relationships or activities that could appear to have influenced the submitted work. 


\section{Cureus}

\section{References}

1. Joshi A, Shrestha PS, Dangol S, Shrestha NC, Poudyal P, Shrestha AA: Stress induced gastric ulcers: presenting as massive rectal bleeding in a newborn. Kathmandu Univ Med J (KUMJ). 2016, 14:186-189.

2. Pai AK, Fox VL: Gastrointestinal bleeding and management. Pediatr Clin North Am. 2017, 64:543-561. 10.1016/j.pcl.2017.01.014

3. Mezoff AG, Balistreri WF: Peptic ulcer disease in children. Pediatr Rev. 1995, 16:257-265. 10.1542/pir.16-7257

4. Goyal A, Treem WR, Hyams JS: Severe upper gastrointestinal bleeding in healthy full-term neonates . Am J Gastroenterol. 1994, 89:613-616.

5. Johnson D, L'Heureux P, Thompson T: Peptic ulcer disease in early infancy: clinical presentation and roentgenographic features. Acta Paediatr Scand. 1980, 69:753-760. 10.1111/j.1651-2227.1980.tb07145.x

6. Man DW: Massive upper gastrointestinal bleeding from haemorrhagic gastritis in the newborn . Aust N Z J Surg. 1986, 56:871-872. 10.1111/j.1445-2197.1986.tb01842.x

7. Pugh RJ, Newton RW, Piercy DM: Fatal bleeding from gastric ulceration during first day of life--possible association with social stress. Arch Dis Child. 1979, 54:146-148. 10.1136/adc.54.2.146

8. Pensabene L, Salvatore S, D'Auria E, et al.: Cow's milk protein allergy in infancy: a risk factor for functional gastrointestinal disorders in children. Nutrients. 2018, 10:E1716. Accessed: January 24, 2020: https://www.ncbi.nlm.nih.gov/pubmed/30423934. 10.3390/nu10111716

9. Kim HJ: The gastric and duodenal eosinophilia in functional dyspepsia . J Neurogastroenterol Motil. 2016, 22:353-354. 10.5056/inm16094

10. Prussin C: Eosinophilic gastroenteritis and related eosinophilic disorders. Gastroenterol Clin North Am. 2014, 43:317-327. 10.1016/j.gtc.2014.02.013

11. Coussons-Read ME: Effects of prenatal stress on pregnancy and human development: mechanisms and pathways. Obstet Med. 2013, 6:52-57. 10.1177/1753495X12473751

12. Lazzaroni M, Petrillo M, Tornaghi R, Massironi E, Sainaghi M, Principi N, Bianchi Porro G.: Upper GI bleeding in healthy full-term infants: a case-control study. Am J Gastroenterol. 2002, 97:89-94. 10.1111/j.1572-0241.2002.05443.x

13. Matsueda K, Toyokawa T, Sakata M, Fujita I, Horii J, Abe Y, Araki T: Hemorrhagic stress-induced gastric ulcer in a healthy toddler. Intern Med. 2018, 57:2833-2886. 10.2169/internalmedicine.0895-18 